\title{
Ataques Cibernéticos: \\ Representações Sociais da pessoa negra na internet
}

Talita Vieira Figueiral Amanda Castro ${ }^{2}$ Ismael de Córdova ${ }^{3}$ Fernanda de Souza Fernandes ${ }^{4}$

\begin{abstract}
Resumo: Esta pesquisa teve por objetivo compreender as representações sociais da pessoa negra por meio de reações à postagens na internet. Para este estudo foram selecionados 69 comentários gerados por 3 redes sociais (instagram, Twitter, Facebook) e blogs pessoais online. Os comentários foram organizados em um único corpus que foi submetido a uma Nuvem de palavras e uma Classificação Hierárquica Descendente (CHD) simples com o auxílio do programa informático IRAMUTEQ. Os resultados encontrados se dividiram em 4 classes 1)A Universidade como algo que foi reduzido com a política de cotas, como um ambiente menos produtivo; 2)Insatisfação com professores de ideologia de esquerda que estimulam políticas de cotas, bem como insatisfação com a Universidade que permite o ingresso de alunos negros e com a grade curricular; 3)Adjetivos como fedida e escrava são utilizados para menosprezar a mulher negra; 4)Estereótipos relacionados à animalização (macaco), criminalidade, empregos relativos à limpeza (empregada doméstica) e vadiagem.
\end{abstract}

Palavras chave: Racismo, Internet, Representações Sociais.

\section{Cybernetic Attacks: Social Representations of the black person on the internet}

\begin{abstract}
This research aimed to understand the social representations of the black person through reactions to internet postings. For this study were selected 69 comments generated by 3 social networks (instagram, Twitter, Facebook) and personal blogs online. The comments were organized in a single corpus that was submitted to a word cloud and a simple descending Hierarchical Classification (CHD) with the help of the IRAMUTEQ software. The results found were divided into 4 classes 1) The University as something that was reduced with the quota policy as a less productive environment; 2) Dissatisfaction with teachers of left-wing ideology who stimulate quota policies, as well as dissatisfaction with the University that allows the entry of black students and with the curriculum; 3) Adjectives such as stink and slave are used to belittle the black woman; 4) Stereotypes related to animalization (monkey), crime, jobs related to cleaning (maid) and vagrancy.
\end{abstract}

Keywords: Racism, Internet, Social Representations.

\footnotetext{
${ }^{1}$ Acadêmica de Psicologia, Universidade do Extremo Sul Catarinense - UNESC, e-mail: thatavf_@ hotmail.com, Criciúma, SC - Brasil;

${ }^{2}$ Mestre em Psicologia Social, Professora do curso de Psicologia da Universidade do Extremo Sul Catarinense, e-mail: amandacastrops@gmail.com, Criciúma, SC - Brasil;

${ }^{3}$ Mestre em Desenvolvimento Socioeconômico, email cordovaismael@ hotmail.com, Criciúma, SC - Brasil;

${ }^{4}$ Mestre em Saúde Coletiva, email fe-psic@ hotmail.com, Criciúma, SC - Brasil.
} 


\section{Introdução}

Segundo IBGE (2014), os negros (pretos e pardos) são a maioria da população brasileira, representando $53,6 \%$ da população. A população negra constitui $(78,9 \%)$ dos $10 \%$ de indivíduos com maiores chances de serem vítimas de homicídios. No Brasil nos dias atuais, de cada 100 pessoas assassinadas, 71 são negras, segundo informações do Atlas da Violência (2017). Esses dados reforçam a necessidade do desenvolvimento de pesquisas que expliquem o pensamento social racista e seus desdobramentos.

A Teoria das Representações Sociais surge como uma das formas de estudar o pensamento social. De acordo com Vala e Monteiro (2002, p.461), as Representações Sociais são resultantes das interações e dos processos de comunicação no cerne de um grupo social, demonstrando a situação desse grupo, os seus projetos, problemáticas e estratégias e a suas relações com outros grupos.

Segundo Jodelet (2001) as representações sociais são formadas quando as pessoas procuram modos para se orientar, para sair da zona do desconhecimento e dominar os assuntos, são mecanismos de resolução de problemas. Desse modo, as representações são formar de conhecer e se aproximar da realidade cotidiana. A gênese das representações engloba dois processos: a objetificação e a ancoragem.

Conforme Folle e Geib (2004), a objetificação torna concreto um conceito, coloca a realidade em plano tangível. Assim as ideias ganham materialidade, tornando-se palpáveis.

Outro processo de formação de representações é a ancoragem. Segundo Folle e Geib (2004), a ancoragem é ocorre quando as ideias ou objetos sociais podem ser associados ou relacionados à outras categorias de conhecimento, ou seja, a ancoragem fornece significado para pessoas, grupos e objetos sociais. Portanto, por meio deste processo o que era estranho se torna algo familiar.

Dentro da Teoria das Representações Sociais, existem as abordagens, que Torres e Camargo (2008) descreve e que foram originalmente criadas por Moscovici. Essas abordagens estudam o processo de formação das representações sociais sob vieses distintos, para compreender o pensamento social, apontando que a representação social se refere a uma produção mental, por meio da construção ou mudança de um objeto. 
A abordagem dimensional entende que as representações sociais se constituem e se dispõem de acordo com as características de cada classe, cultura ou grupo, sendo definida por meio de três dimensões que é a informação, onde procura identificar todas as informações (quantidade e qualidade) que o sujeito ou o grupo tem sobre o objeto de pesquisa. A atitude, que é a preparação para ação, onde se verifica se os indivíduos tem atitude favoráveis ou não sobre o objeto estudado. E o campo de representação, que é a imagem que se forma a partir dos conhecimentos gerados, permite visualizar o conjunto de conhecimentos que o grupo apresenta sobre um objeto e a articulação a respeito destes conhecimentos (TORRES; CAMARGO, 2008; FERREIRA; BRUM, 2000).

Torres e Camargo (2008) descrevem a abordagem dinâmica de Jodelet, que se propõe a estudar como as representações sociais intervém no cotidiano, com enfoque na gênese: ancoragem e objetificação. Assim, a realidade é formulada no seu sistema cognitivo, interligada às normas subjetivas, contexto sociocultural, englobando aspectos afetivos, mentais e sociais, associados à cognição, comunicação e linguagem.

Almeida (2009) discute em seu artigo sobre a abordagem societal, a autora traz que essa abordagem busca conectar o individual ao coletivo, enfatizando que os processos de que os indivíduos possuem para viver em sociedade são conduzidos por aspectos sociais, englobando valores, interações, crenças, mas também individuais, sob o aspecto cognitivo e de personalidade.

Campos e Rouquette (2003), para explicar a abordagem estrutural, se baseia nos autores Abric, Flament, Rouquette e Rateau que a definiram. Essa abordagem procura estruturar relações de primazia entre os aspectos cognitivos e afetivos. Assim, procura-se localizar aspectos afetivos e cognitivos que estruturam o núcleo e os elementos que atuam na periferia de uma representação, ou seja, os elementos mais rígidos e mais flexíveis da representação social.

Neste artigo se trabalhará a partir das abordagens, dimensional, dinâmica e societal. Pois, interessará identificar o racismo a partir de afetos, posicionamentos, informação, origem das representações, grupo de pertença e a relação entre esses fatores.

A forma como as pessoas representam o mundo afeta as práticas sociais, interferindo ou gerando possíveis atitudes discriminatórias. Um exemplo é o estudo de Costa e Santos (2014), que traz uma pesquisa sobre as representações sociais de professores de educação infantil sobre a criança negra e as consequências na socialização da criança no espaço educacional. 
Nessa pesquisa foram trazidas algumas atividades para as crianças e numa delas era uma encenação de um conto infantil, onde havia um rei, uma rainha, uma princesa e uma bruxa má, no entanto, na escolha das crianças para estes personagens os professores se preocuparam em escolher as crianças pelas características estéticas dos personagens, como o rei, a rainha e princesa eram crianças brancas e a bruxa má uma menina com cabelos crespos, bem volumosos. Nesse sentido, as crianças ratificavam a escolha, ao dizerem que o cabelo da R1 (menina) parecia mesmo ao de uma bruxa. Foi observado que os diálogos entre as professoras e as crianças e seus pares, revelam que não existe nada de inocente naquilo que as crianças aprendem sobre a questão racial. Este fato, mostra que cabe ao professor o papel de agente ativo na mediação e intervenção no trato às diferenças, garantindo que este espaço/tempo vivenciado pelas crianças brancas e pelas crianças negras na educação infantil, seja constituído pelo diálogo, reconhecimento e respeito à diversidade racial na escola, a partir de uma prática pedagógica transformadora, inclusiva e libertadora contribuindo para a efetivação de uma sociedade intercultural (COSTA; SANTOS,2014).

Outro Estudo sobre as representações sociais, foi de Melo et al. (2014), que fala das representações sociais de estudantes sobre as cotas universitárias. Nele foi aplicado um questionário para 66 estudantes de diferentes raça/cor/etnia. Uma das perguntas desse questionário foi: Quais as cinco palavras lhe vem à mente quando você ouve a expressão cotas universitárias'? As evocações com maior frequência cuja ordem de evocação seja inferior à ordem média são escola pública, inclusão, negro, Igualdade, oportunidade e reparação. Há também os termos discriminação, desigualdade, preconceito e separação que podem ser interpretados em sentidos ambivalentes.

As evocações de menor frequência acesso, direito e democracia. É possível pensar que os estudantes, de uma maneira geral, acreditam que as cotas podem refletir uma injustiça (sendo que há a crença de que as cotas são eminentemente raciais), pois o problema da falta de diversidade na academia lhes parece ser social. Os dados da pesquisa sugerem que, em uma década de existência do sistema de cotas universitárias no Brasil, de maneira geral, os estudantes, tem uma concepção sobre tal sistema que não se distancia muito de como ela está proposta legalmente, apesar de algumas diferenças de ideias quando investigado sobre as cotas e sobre o cotista.

Araújo (2014), fez uma releitura das representações do negro no filme Gamga Zumba de 1960, para analisar as discussões a cerca do negro no cinema brasileiro. Foi o primeiro filme 
brasileiro que um negro foi protagonista, mas no filme mostra como o negro era um sujeito inferiorizado, semelhante a um animal, também foram observados que os arquétipos condicionados ao negro sempre foi feita de forma desmerecedora, a sexualidade do negro não era vista da mesma forma que a dos brancos, mas sim igualmente a dos animais. A historiografia brasileira sobre influenciada de ideias evolucionistas, fez a retração do negro não colocando como agente sujeito da história, mas como sujeito objeto que o teria para oferecer seria apenas a força de trabalho que fez acelerar a economia do Brasil, no período Colonial. É perceptível que o negro ganhou espaço dentro do cinema novo brasileiro, isso se dá pela participação dos movimentos negros existentes, mas fica nítido que o mesmo ainda não ocupa um lugar social e cultural devidamente cabível a ele.

Souza (2017), também faz uma reflexão crítica em seu artigo acerca da personagem negra na dramaturgia brasileira. A autora destaca a ausência de protagonistas negros. Entretanto, quando a personagem negra surge esta é representada na imagem do escravo ou empregado; nesse contexto ou os personagens são inferiorizados ou fetichizados. Deste modo, a autora revela como os estereótipos raciais estão presentes nas novelas sustentando discursos racistas. Ela também observou o quanto é importante rediscutir o espaço da pessoa negra na televisão.

Gouvêa (2005), também estuda as imagens do negro, fazendo uma análise historiográfica da literatura infantil brasileira nas primeiras décadas do do séc XX, que foi proclamado e celebrado como o "século da criança". O Autor discute a centralidade da infância na cultura contemporânea, em que partindo da ideia de singularidade dessa fase e da separação da adultez é direcionado todo um mercado de bens simbólicos para a infância. Nos textos utilizados pelo autor, datados entre 1900 e 1920, o negro quando fazia parte do enredo restringia-se à cena dos serviços domésticos, sendo majoritariamente mudos e sem caracterização para além de uniformes ou roupas de escravos. Tais textos parecem se alicerçar no embranquecimento do leitor, sustentados em um posicionamento racista.

Miranda (2015) entende o racismo como uma ideologia que se sustenta mesmo na ausência de evidências empíricas ou cientificas da superioridade ou da inferioridade de uma raça em relação as demais. Tal ideologia segue como construção mental justificadora, atuando sobre o conjunto de leis psicológicas que conduzem os processos cognitivos e afetivos. E entre esses processos cognitivos que embasam ideologias racistas, destacam-se os processos de 
categorização e de elaboraçãoj de estereótipos, com seu papel justificador nas relações intergrupais.

De acordo com Sawaia (2001), estereótipos são estruturas que dizem respeito à características atribuídas aos membros de um grupo ou de uma categoria social. São decorrentes de processos de simplificação cognitiva, inerentes ao senso comum.

Quando se fala em racismo, também se pensa no preconceito, Sawaia (2001) conceitua o preconceito como um julgamento positivo ou negativo de uma pessoa ou de uma coisa e que, assim, compreende vieses e esfera específicas. Sua forma (estereotipia), é uma dimensão afetiva ligada às emoções e valores engajados na interação com o alvo, uma dimensão conativa, a descrição positiva ou negativa.

A discriminação também faz parte do racismo, nas sociedades humanas é uma prática disseminada. Onde existe a diferença, existem indivíduos cujas vidas são prejudicadas por pertencerem a um ou outro grupo que foge a determinadas normas, como exemplo, a cor da pele.

Uma das formas de manifestação de preconceito e racismo ocorre nas redes sociais. De acordo com Recuero (2014) as redes sociais na internet não são estáticas, estão em constante fluxo de mudanças. Tais mudanças se originam dos processos de interações entre os indivíduos. A interação social é compreendida como geradora dpropicia a gênese dos processos sociais a partir de seus padrões na rede, identificados como competição, cooperação e conflito (RECUERO, 2014, p. 80). O Facebook é uma rede social online, onde os usuários constroem os seus perfis, com fotos e descrições, tendo a possibilidade de trocar mensagens, públicas e privadas, além de constituir amigos e participar de grupos (CORREIA; MOREIRA, 2014). Por meio do facebook as pessoas expressam suas opiniões, sentimentos e desejos. Correia e Moreira (2014) define o facebook como um website, que vincula páginas de perfil dos seus usuários. Nestas páginas os usuários mantém informações sobre si próprios, vinculando seus perfis aos de outros usuários.

No facebook as pessoas demonstram sua identidade social. Identidade social está ligada ao conhecimento de indivíduo acerca da sua pertença a certos grupos sociais e a significação emocional e avaliativa que resulta desta pertença (VALENTIM, 2008). Mais do que evidenciar sua identidade social o facebook também se transformou em ferramenta de manifestação de representações sociais segregadoras e preconceituosas. O estudo de Soares (2016) demonstra isso. A autora analisou os comentários no facebook sobre uma torcedora que cometeu racismo 
dentro do estádio de futebol na hora do jogo. Pelo fato de ser mulher a torcedora foi mais agredida. Soares (2016) identificou que a maioria se dirigia diretamente à xingamentos relacionados à condição de ser mulher da torcedora em questão, percebe-se que o discurso enraizado das culturas e das hierarquias, que vão desde os menores grupos até instituições significativamente maiores, influencia diretamente na relação que as pessoas vão estabelecer entre si e com os outros, estando em rede. Soares (2016) também afirma que o fato de esses comentários estarem em uma rede com laços sociais fracos, ajuda a entender que é um discurso que se propaga no meio online em diversos grupos, e que é legitimado pela maioria. A violência é combatida com violência e poder de colocação do outro em um lugar menor, no qual a punição vem pela exclusão dos grupos sociais, dentre os quais se destaca a questão de gênero.

Os autores Silva e Braga (2016) realizaram um estudo sobre racismo e sexismo que mulheres negras sofrem no facebook. Esse estudo foi realizado através de perguntas abertas a mulheres negras. Foi perguntado à elas se acreditam que o facebook propicia a agressão, todas as respostas foram iguais, confirmando a agressão, pois pelo fato dos usuários poderem criar perfis falsos, podem falar o que quiserem sem receio. Também há a liberdade de expressão fornecida nessa rede, em que se produz textos sem que eles passem por nenhum tipo de revisão ou edição, e por fim tem a situação em que se encontra o agressor, que geralmente não está perto da vítima no momento da publicação, o que faz com que ela não possa revidar, já que não se tem um contato físico (SILVA; BRAGA, 2016).

Moura (2015) traz outro estudo que mostra atos violentos através de mídias online, ela busca refletir sobre a reprodução do racismo no Imaginário Social brasileiro. A partir das análises de vários comentários retirados do facebook, observou-se que as ocorrências apresentadas se orientam por um discurso no qual o negro é associado à figura de um animal, relacionado à elementos da escravidão, sustentados na ideia de que este não apresenta condições de ser considerado humano.

De modo similar, Silva et al. (2016) fazem um estudo sobre o Preconceito nas Mídias Sociais, fazendo uma análise do caso de racismo Sofrido pela Atriz Taís Araújo no Facebook. No caso da atriz, foi observado que através da análise do discurso que os agressores discriminaram a atriz pela sua cor, cabelo, entre outros aspectos físicos, tendo como base de referência um racismo cultural e histórico, que transcende qualquer sentimento de respeito e humanização do indivíduo. 
Tendo em vista o fenômeno do racismo nas redes sociais este artigo se propõe a compreender as representações sociais da pessoa negra por meio de reações à uma postagem no Facebook.

\section{Método}

A pesquisa teve um enfoque qualitativo, exploratório, descritivo e transversal. De acordo com (GERHADT; SILVEIRA, 2009) A pesquisa qualitativa busca apurar e aprofundar a compreensão de determinados grupos sociais e organizações, sem se preocupar com provas ou dados numéricos, sendo seu objetivo demonstrar aspectos da realidade centrando-se na explicação das dinâmicas das relações sócias.

Para este estudo foram selecionados comentários gerados por 3 redes sociais (instagram, Twitter, Facebook) além de blogs pessoais online. Foram utilizadas como palavras de busca: racismo online, racismo facebook, racismo twitter, ataques racistas na internet, no google e foram selecionados comentários públicos gerados em 2017. Foram analisados 69 comentários, dentre posts em redes sociais e blogs.

Os comentários foram elencados em um único corpus que foi passou por análises via a uma Nuvem de palavras e Classificação Hierárquica Descendente (CHD), para tanto foi utilizado o programa informático IRAMUTEQ versão 0.6. Conforme Camargo e Justo (2013) esta análise tem por objetivo obter classes de Segmentos de Texto (ST) que entre si apresentam vocabulário semelhante e em relação à outras classes apresentam conteúdo semântico diferente. (Camargo e Justo 2013).

Na Classificação Hierárquica Descendente (CHD) cada classe é formada por vários segmentos de texto com classificação segundo o conteúdo semântico destes segmentos (CAMARGO; JUSTO, 2013). As classes formadas com base na classificação hierárquica descendente podem sugerir elementos de representações sociais (CAMARGO, 2005). Após Classificação Hierárquica Descendente (CHD) simples, foram inseridos em cada classe elementos com frequência maior que a média de ocorrências no corpus e cuja associação com a classe identificada pelo valor de qui-quadrado fosse igual ou superior a 3,84, neste artigo o mínimo foi de 5,96. 


\section{Resultados}

O programa IRAMUTEQ reconheceu a separação do corpus em 69 textos ou comentários. A CHD reteve 66 textos, 95,6\% do total, e dividiu o corpus em quatro classes, conforme indica a Figura 1.

Figura 1 - Dendograma de classes sobre as as representações sociais da pessoa negra na internet.

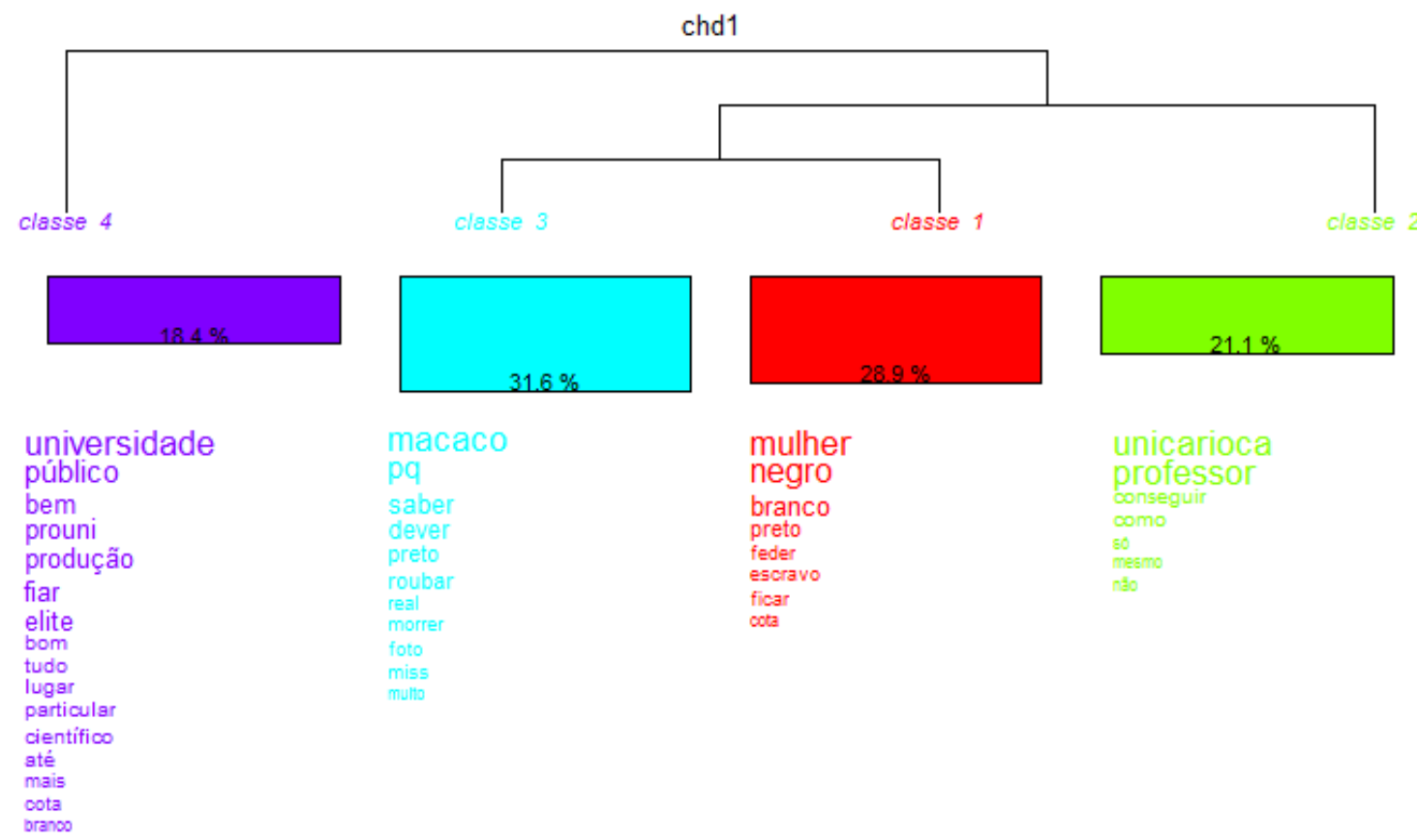

Fonte: autora.

Num primeiro momento ( $1^{\mathrm{a}}$ partição) o corpus foi segmentado em dois sub corpus (de um lado um conjunto formado pelas futuras classes 2,1 e 3 e do outro pela classe 4). Uma $2^{\mathrm{a}}$ partição originou as classes 2 ; e uma $3^{\text {a }}$ partição gerou as classes 1 e 3.

A classe Privilégio Branco, presente principalmente em blogs e no Twitter, com 18,42\% dos comentários (Classe 4), traz referências à Universidade como algo que foi reduzido com a política de cotas, como um ambiente menos produtivo intelectualmente e mais favorável à posição política de esquerda. O Prouni é descrito como uma forma de ingresso que atrai a 
população negra e a ideia de Universidade paga surge como alternativa para embranquecer o ambiente acadêmico. Nessa perspectiva a população branca é tida como injustiçada, pois tem que pagar Universidades, enquanto os negros estudariam gratuitamente. O Trecho abaixo exemplifica o conteúdo desta classe de comentários:

\begin{abstract}
O que me deixa mais calmo é que quando o Bolsonaro virar presidente em 2018, a primeira coisa que ele vai fazer é acabar com essas merdas de cotas, PROUNI e FIES, $e$ ainda vai colocar mensalidades nas universidades públicas. Sendo assim as universidades voltarão a ser um lugar de produção de conhecimento por pessoas brancas e de bem e não palanque pra macacos cotistas e bolsistas (Comentário em um blog de conteúdo racista, 2017).
\end{abstract}

A classe 2, denominada Ideologia de Esquerda, apresenta 21,05\% do total de comentários, presentes em blogs e no Instagram. Seus elementos estão associados principalmente ao posicionamento dos indivíduos sobre à insatisfação com professores de ideologia de esquerda que estimulam políticas de cotas, bem como insatisfação com a Universidade que permite o ingresso de alunos negros e com a grade curricular, associando o MEC e cursos de humanas á esta mesma ideologia. Seu conteúdo engloba palavras como: unicarioca, professor e conseguir, conforme o exemplo a seguir.

\footnotetext{
$O$ que se vê são mestiços e negros poluindo o ambiente, professores descompromissados e relapsos, e uma forte tendência à implantação forçada de ideologias de esquerda doutrinadas pelas grades curriculares do MEC. Hoje, a Unicarioca não produz nada além da pária social e acadêmica: esquerdistas que tiraram o diploma empurrando o seu curso na barriga principalmente os de humanas, onde há o tipo de aluno mais repulsivo que se pode imaginar (Comentário em um blog de conteúdo racista, 2017).
}

Em oposição à classes 2 estão as classe 1 e 3. A classe Estética da Mulher Branca (Classe 1), representa $28,95 \%$ do total de comentários. Esta classe, presente principalmente na rede social Instagram, apresenta elementos relativos principalmente à beleza da mulher branca em oposição à mulher negra. Alisar o cabelo ou o uso da maquiagem, são critérios utilizados nos comentários para demonstrar que a mulher negra deseja embranquecer. Esta é acusada de ter inveja da branca, sendo considerada resto ,na escolha masculina. Adjetivos como fedida e escrava são utilizados para reduzir e menosprezar a mulher negra. $\mathrm{O}$ homem negro neste contexto é igualmente ofendido, mas por sua vez é acusado de preferir as mulheres brancas, por considerarem-nas as mais belas, sendo vistos como os mais racistas. $\mathrm{O}$ trecho que segue ilustra essa classe: 
A solidão da mulher preta é real, ninguém gosta de mulher preta, ninguém quer, nem pra estuprar, nem negros quer, a gente não ensina a estuprar mulheres pretas porque o pau nem sobe pra elas, não vale a pena, negras tem inveja de brancas que precisam alisar o cabelo pra ficar igual, tiram fotos com o flash alto pra clarear a pele, negras fedem a catinga, a mulher preta fede por natureza, não estamos mais na senzala pra deitar com escravas (Comentário em um post no Instagram, 2017).

A Classe 3, denominada Estereótipo relativo ao negro, representa 31,58\% de comentários retidos na análise, principalmente via Facebook e Twitter, sendo dirigida majoritariamente à artistas e jogadores de futebol. Seu conteúdo abrange aspectos de estereótipos (objetivação da representação social) relacionados à animalização (macaco), roubo, criminalidade, empregos relativos à limpeza (empregada doméstica) e vadiagem. As palavras negro, preto e escuro são utilizadas propositadamente para adjetivar acontecimentos ruins, numa perspectiva de duplo sentido. Os segmento de texto abaixo demonstra essa classe: Não pago energia pra ver essa macaca na televisão. To vendendo essa escrava a 200 reais, no momento a emprestei pra globo. Fui tentar dar like mas a macaca roubou o botão. Você é uma vagabunda, toda vez que vejo você penso que vai chover, tudo preto nessa porra (Comentário em um post no Facebook, 2017).

Dessa forma, os principais resultados, com as palavras de maior frequência, nos discursos, podem ser ilustrados na nuvem de palavras abaixo:

Sou a favor das cotas, mas acredito que deveria ser uma política com prazo determinado até que as escolas públicas estivessem no mesmo nível das particulares. Só assim as oportunidades seriam iguais. De qualquer forma a população negra ainda enfrenta um muro invisível que fecha muitas portas (comentário 148).

Desse modo, na classe 2 há a presença de maior favorabilidade ao sistema de cotas. Nessa classe estão presentes 37 comentários que apresentam elementos a favor ao sistema de cotas como medida provisória, justificada pela desigualdade entre ensino público e ensino privado. Em relação às demais classes não há prevalência geral em relação à favorabilidade ou desfavorabilidade ao sistema de cotas para negros em Universidades Federais. A maioria dos participantes (127 comentários) apresentam posicionamento neutro em relação à política de cotas, não se posicionando diretamente à favor ou contra as cotas para negros em Universidades Federais. Os comentários com posicionamento neutro não apresentam implicação pessoal que 
remeta à favorabilidade ou desfavorabilidade do internauta, sendo seu foco a discussão de aspectos políticos e sociais.

Dessa forma, os principais resultados, com as palavras de maior frequência, nos discursos, podem ser ilustrados na nuvem de palavras abaixo:

Figura 1 - Nuvem de Palavras com a síntese dos resultados

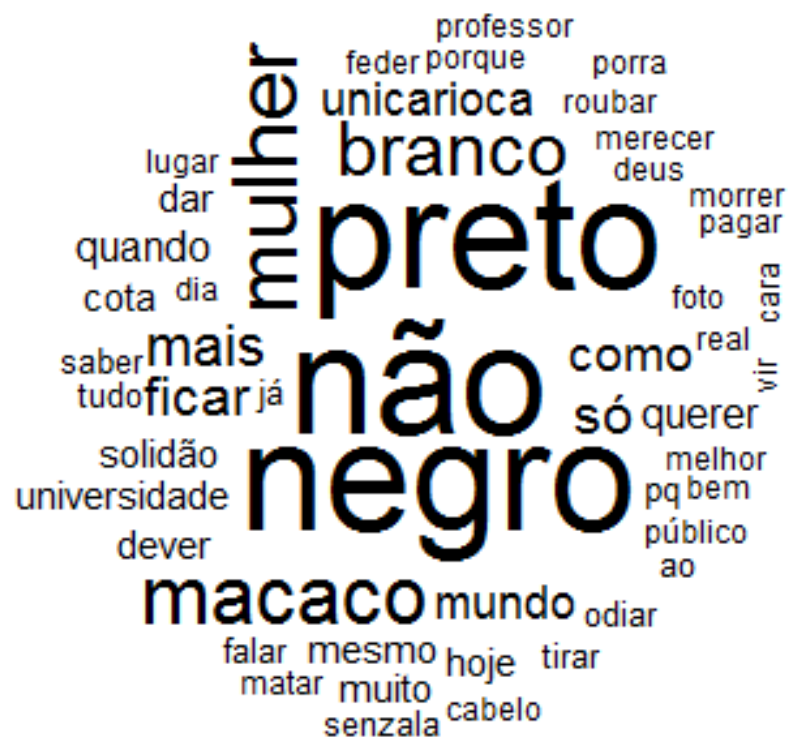

Fonte: autora.

\section{Discussão}

A classe denominada como Privilégio Branco, traz comentários acerca da suposta injustiça vivenciada pelas pessoas brancas, no que concerne ao sistema de cotas que permite a entrada de pessoas negras e pobres nas Universidades, com pontuações distintas em relação às das pessoas brancas. Outra perspectiva é apresentada em pesquisa de Lemos (2017) em que os cotistas negros entrevistados afirmavam que a política de cotas os faziam sentir inferior, enquanto a verdadeira desigualdade estaria nas condições socioeconômicas. Entretanto a pesquisa de Moreira (2017) retrata diferente discurso, apresenta a política de cotas como contrária à meritocracia e de difícil apreensão por levar em consideração a singularidade da experiência social em um país como o Brasil. Nesse sentido a as ações afirmativas devem ser 
discutidas por aqueles que por ela são contemplados, que vivem essa experiência social impregnada de estereótipos que estigmatizam e fomentam a discriminação na Universidade e no mercado de trabalho. Como destaca Moreira (2017, p. 405):

\begin{abstract}
Como o privilégio racial é algo muitas vezes invisível para os seus beneficiários, várias pessoas brancas imediatamente condenam mudanças nos arranjos institucionais que lhes garantem as mais diversas vantagens. Os que dizem não ser racistas facilmente se voltam contra políticas sociais que modificam as prioridades estatais, prioridades que sempre tiveram como foco os interesses das classes dominantes, que também são os grupos raciais dominantes.
\end{abstract}

Assim, a Classe Privilégio Branco apresenta a entrada das pessoas negras na Universidade como uma ameaça às vantagens já adquiridas pelos grupos dominantes. Guimarães (1999) traz que a discussão sobre as políticas de ações afirmativas, especificadamente sobre as cotas universitárias, está envolta no debate de duas posições. A posição histórica e sociológica compreende a condição sociohistórica como elemento justificador das ações afirmativas. A segunda perspectiva, semelhante com os dados aqui apontados é de ordem normativa, compreende as cotas como um elemento de segregação e injustiça social, diferenciando os indivíduos. Nesse sentido, esta perspectiva parece sustentarse na ideia de que a entrada via cotas acarretaria em uma injustiça social, entretanto parece apresentar em sua zona muda (ideia implícita) a noção de que ao entrar na Universidade o negro desorganiza as estruturas de poder vigentes.

A classe denominada Estética da Mulher Branca, traz os comentários racistas menosprezando e inferiorizando a mulher negra, comparando-as com a mulher branca. Nesse contexto, a mulher branca é apresentada como modelo e a negra é preterida com adjetivos como fedida e macaca. Atualmente, o quadro vivido pelas mulheres negras não é tão diferente do período colonial, pois segundo Nascimento (2016), o que ocorreu no Brasil foi uma falsa abolição da escravatura negra, pois desde então os negros e negras vivem a margem da sociedade lutando por sua verdadeira liberdade, de um lado um corpo sexualizado, objetificado e de outro a discriminação por ser mulher e por ser negra. Assim, ainda hoje, ser mulher já coloca a negra sua outra condição minoritária, o que injeta duplo preconceito social.

Nascimento (2016) ressalta que as alocações das mulheres negras no mercado de trabalho em posições mais subalternas não constituem uma escolha delas próprias, por conta das desigualdades há a precarização do trabalho feminino negro. Sobre esse tema, Gomes (2002) discute em sua pesquisa de reprodução de estereótipos, a importância da discussão da 
escola como instituição formadora não só de saberes escolares como, também, sociais e culturais.

[...] alguns estudiosos do campo da educação e da cultura têm destacado o peso da cultura escolar no processo de construção das identidades sociais, enfatizando a escola como mais um espaço presente na construção do complexo processo de humanização. Por essa perspectiva, a instituição escolar é vista como um espaço em que aprendemos e compartilhamos não só conteúdos e saberes escolares, mas também valores, crenças, hábitos epreconceitos raciais, de gênero, de classe e de idade (GOMES, 2005).

Portanto, a autora evidencia em sua pesquisa que para a maioria das mulheres negras jovens e adultas, na faixa dos 20 aos 60 anos, a construção subjetiva do corpo, a partir da experiência com o corpo negro e o cabelo crespo, se expande desde à laços familiares, de amizade, de luta ou de relacionamentos, até a vida escolar. A trajetória escolar surge em todos os depoimentos como um marco no processo de construção da identidade negra e, infelizmente, surge como um campo de construção e reforço de estereótipos e representações negativas sobre essa população e o seu padrão estético (GOMES, 2005). Nesse sentido, a escola surge como um forte propagador de representações, que podem fortalecer ações discriminatórias ou discursos que favoreçam a autoestima.

A Classe denominada Estereótipo relativo ao negro, mostra várias formas de como pessoas racistas veem e classificam os negros, reduzindo-os à características negativas. De acordo com Moreira (2017) os estereótipos raciais não apenas enfatizam hipotéticas características de membros de um grupo, mas também apontam os lugares que se deseja que essas pessoas ocupem dentro de uma sociedade, segregando e limitando. Almeida (2016) esclarece que o aprendizado acerca dos estereótipos ocorrem ainda na infância e em razão disso, se cristalizam nas memórias. A autora desenvolveu uma pesquisa com 58 crianças negras, que apresentavam idades entre 08 e 11 anos. Estas foram convidadas a se autodenominarem quanto a sua cor de pele, e também foram convidadas a expor seus pensamentos acerca da associação de traços estereotípicos relativos à beleza, riqueza, inteligência, bondade, contato e proximidade frente a dois alvos (fotos de uma criança negra e outra branca) apresentados em imagens. Nessa pesquisa a autora pode fazer a seguinte análise:

Historicamente, os atributos físicos ditos dos negros são geralmente pensados de forma mais negativa e postos em comparação desfavorável aos ideais estéticos ("cabelo ruim, duro", "Bombril" (palha de aço); "nariz chato, grosso"). Neste sentido, pondera-se quanto à identidade social destas crianças, que se pensada em termos de 
afiliação emocional, podem apresentar uma busca pelo pertencimento ao grupo dos brancos, ao mesmo tempo que também se afastam deste, fazendo-as elencar características ou estereótipos positivos acerca de si e do grupo (ALMEIDA, 2016, P. 8).

A pesquisa de Almeida (2016) faz refletir nas mudanças acerca das crenças relativas ao negro, fortalecidas pelo movimento negro, que provoca um aumento da autoestima e autoconfiança, que se apoiam na perspectiva de que a criança consegue refletir acerca da realidade que vive, e suas expressões comportamentais e linguísticas são contextualizadas com base na sua própria vivência. Nesse sentido é principalmente na infância que devem surgir esforços coletivos de mudanças de elementos de representações cujo núcleo seja o preconceito. Mas é importante que novas representações sejam propagadas por meio do protagonismo negro nas discussões sociais e de políticas públicas.

A classe 2, denominada Ideologia de Esquerda, apresenta conteúdo referente aos professores tidos como de ideologia de esquerda que estimulam políticas de cotas e discussão sobre o assunto. Em sua pesquisa Soares (2012) afirma que na década de 1970, as organizações de esquerda apresentavam em sua pauta a questão racial. $\mathrm{O}$ projeto político partidário de esquerda da década de 1980, centrado na luta de classes, atraiu a militância negra para o partido. Entretanto, mais que esse aspecto histórico, que pode ter influenciado na ancoragem dessa representação, via partido político, tenta-se destruir o discurso estigmatizando seus autores, no caso desqualificando os professores. Assim, de acordo com Tapajós (2007) a desqualificação insere um ruído na comunicação: responde sem responder. Ocorre na comunicação de pessoas que querem rapidamente fugir de situações que, de alguma forma, parecem-lhe difíceis, nas quais essas pessoas preferem não comunicar. Portanto, essa classe apresenta oposição àqueles que defendem políticas inclusivas para a população negra, tentando desconstruir as pessoas que as defendem e não seus discursos.

A influência da internet na circulação de representações e propagação de preconceito é grandiosa, pois Castro et al. (2014, p. 207) afirmam:

No século XXI, a internet se constitui como uma das principais fontes de comunicação e, com sua intensa e rápida possibilidade de troca de informações, permite uma relação fluida de troca de papéis entre o produtor e o receptor da informação. Assim, torna a informação independente de seu produtor, permite diálogos entre pessoas e grupos, constituindo-se em um espaço para discussão e elaboração de representações.

Dessa forma podemos entender a força que a internet tem na disseminação do preconceito, pois é um meio de comunicação que proporciona a aproximação entre as pessoas 
de todo o mundo, tendo no anonimato a fuga para demonstração de atitudes discriminatórias.

\section{Considerações Finais}

Quando pronunciada as palavras negro, preto e escuro, essas são utilizadas propositadamente para adjetivar acontecimentos ruins, dessa forma é possível entender, a partir das representações sociais, a forma como o negro é visto pela sociedade.

Após análise dos textos e comentários em diversas redes sociais e blogs, percebeu-se o modo de como a pessoa negra é representada na sociedade, essa representação ainda ocorre de forma discriminatória e preconceituosa. Muitos desses ataques racistas acontecem pelo fato das pessoas acreditarem que se comunicando pela internet estão protegidas, e dessa forma podem expressar o que pensam.

Verificou-se que os estereótipos referentes à pessoa negra e a forma como são colocados e escritos nas redes sociais e blogs, têm por objetivo agredir psicologicamente e inferiorizar a pessoa negra. Quando surge o primeiro comentário racista na foto de uma pessoa negra, este estimula mais pessoas racistas a comentarem e ajudarem a difamar a imagem dessa mesma pessoa. Esse fenômeno decorre de conflitos intergrupais, em que para favorecimento do seu grupo de origem estes se unem para se separar de um outro grupo, como forma de se manterem supostamente na superioridade (TAJFEL, 1982).

Tendo em vista que esta pesquisa ocorreu via documentos online, sugere-se para futuras pesquisas uma pesquisa de campo, entrevistas com as pessoas negras que sofreram e sofrem ataques racistas pela internet. Outro questionamento que fica deste trabalho é: Após sofrerem ataques de preconceito, como lidam emocionalmente com essa situação, procuram ajuda? Denunciam?

Depois de analisar todos os comentários na internet e pesquisas sobre a pessoa negra, fica nítido que a mesma ainda não ocupa seu lugar social e cultural de direito, estando suscetível à representações que tem por função marginalizar essa população. Faz-se necessário o desenvolvimento de um programa para combater o racismo na infância, alterando as representações durante a sua formação. Sugere-se portanto intervenções em grupos, principalmente nas universidades e escolas, com o fim de debater e oportunizar espaços de fala para a população negra, oportunizando alterações na periferia das representações, até que algum 
dia modifique-se o núcleo destas.

\section{Referências}

ALMEIDA, A.M.O. Abordagem societal das Representações Sociais. Sociedade e Estado, v. 24, n. 3, p. $713-737,2009$.

ALMEIDA, S.S.M. Análise de traços e conteúdos estereotípicos de uma amostra de crianças negras. Revista Psicologia em Foco, v.8, n.11, p. 3 - 14. 2016.

ARAUJO, P.J.S. Uma releitura das Representações Sociais do negro no filme Ganga Zumba. 2014. 42 f. Trabalho de Conclusão de Curso (Licenciatura em História) - Universidade Estadual da Paraíba, Campina Grande, PB, 2014.

CAMARGO, B.V. ALCESTE: um programa informático de análise quantitativa de dados textuais. Perspectivas teórico-metodológicas em representações sociais, v. 1, p. 511-539, 2005.

CAMARGO, B.V., JUSTO, A.M. IRAMUTEQ: um software gratuito para análise de dados textuais. Temas em psicologia, v. 21, n. 2, p. $513-518,2013$.

CAMPOS, P.H.F., ROUQUETTE, M.L. Abordagem estrutural e componente afetivo das Representações Sociais. Psicologia: Reflexão e Crítica, v. 16, n. 3, p. 435 - 445, 2003.

CASTRO, A., et al. Representações Sociais na internet sobre cotas para negros em universidades federais. Caderno de Pesquisa Interdisciplinar em Ciências Humanas, v. 15, n. 106, p. 202 - 220, 2014.

CERQUEIRA, D., et al. Atlas da Violência 2017. Ipea, n. 18, 2017. Disponível em: <http://www.ipea.gov.br/atlasviolencia/download/2/2017>. Acesso em: 04 jun. 2017.

CORREIA, P.M.A.R., MOREIRA, M.F.R. Novas formas de comunicação: história do Facebook- uma história necessariamente breve. Alceu, v. 14, n. 28, p. 168 - 187, 2014.

COSTA, R.A., SANTOS, T.R.L, Representações Sociais de professores de Educação Infantil sobre a criança negra. Revista de Administração Educacional, v. 1, n. 2, p. 115 - 138, 2014.

FERREIRA, S.R.S., BRUM, J.L.R. As Representações Sociais e suas contribuições para o campo da saúde. Revista Gaúcha de Enfermagem, v. 20, n. esp., p. 5- 14, 2000.

FOLLE, E., GEIB, L. T. C. Representações Sociais das primíparas adolescentes sobre o cuidado materno ao recém-nascido. Rev Latino Americana de Enfermagem, v. 12, n. 2, p. 183 - 190, 2004.

GERHARDT, T.E; SILVEIRA, D.T. (Org.). Métodos de pesquisa. Porto Alegre: Editora da UFRGS, 2009.

GOMES, N.L. Trajetórias escolares, corpo negro e cabelo crespo: reprodução de estereótipos ou ressignificação cultural? In: BRASIL. Secretaria de Educação continuada, Alfabetização e Diversidade. Educação como exercício de diversidade. Brasilia: SECAD, 2005. p. 227 - 247. 
GOUVÊA, M.C.S. Imagens do negro na literatura infantil brasileira: análise historiográfica. Educação e Pesquisa, v. 31, n. 1, p. 77 - 89, 2005.

GUIMARÃES, A.S.A. Racismo e anti-racismo no Brasil. São Paulo: Editora 34 LTDA, 1999.

INSTITUTO BRASILEIRO DE GEOGRAFIA E ESTATÍSTICA - IBGE. Cidades@: Rio de Janeiro. 2014. Disponível em: <https://biblioteca.ibge.gov.br/visualizacao/livros/liv63405.pdf>. Acesso em: 04 jun. 2017.

JODELET, D. Representações Sociais: Um domínio em Expansão. Paris, França: PUF, p. 31 - 61, 2001.

LEMOS, I.B.D. Narrativas de cotistas raciais sobre suas experiências na universidade. Revista Brasileira de Educação, v. 22, n. 71, p. 1 - 25, 2017.

MELO, C.V.G., et al. Representações Sociais de estudantes da UFBA sobre as cotas universitárias. Psicologia e Saber Social, v. 3, n. 1, p. 55 - 69, 2014.

MIRANDA, R.S. Racismo no contexto da saúde: um estudo psicossociológico. 2015. 194 f. Tese (Programa de Pós Graduação em Psicologia Social) - Universidade Federal da Paraíba, João Pessoa, PB, 2015.

MOURA, T.M. Racismo nas Redes Sociais: perpetuação do imaginário social de inferiorização do negro na sociedade brasileira. Emblemas, v. 12, n. 2, p. 42 - 51, 2015.

MOREIRA, A.J. Pensando Como Um Negro: Ensaio De Hermenêutica Jurídica. Revista de Direito Brasileira, v.18, n. 7, p. $393-420,2017$.

NASCIMENTO, A. O genocídio do negro brasileiro: processo de um racismo mascarado. São Paulo: Editora Perspectiva AS, 2016.

RECUERO, R. Curtir, compartilhar, comentar: trabalho de face, conversação e redes sociais no Facebook. Verso e Reverso, v. 28, n. 68, p. 114 - 124, 2014.

SAWAIA, B (Org). As artimanhas da exclusão: Análise psicossocial e ética da desigualdade social. Rio de Janeiro: Vozes, 2001.

SILVA, T.P., BRAGA, C.F. Racismo e sexismo sofrido por mulheres negras no Facebook. In: CONGRESSO BRASILEIRO DE CIÊNCIAS DA COMUNICAÇÃO, 39, São Paulo. Anais Eletrônicos... São Paulo: INTERCOM, 2016. Disponível em: 〈http://www.intercom.org.br〉. Acesso em: 04 jun. 2017.

SILVA, T.P., et al. O preconceito nas mídias sociais: Análise do caso de racismo sofrido pela atriz Taís Araújo no Facebook. In: CONGRESSO DE CIÊNCIAS DA COMUNICAÇÃO CENTRO-OESTE, 35, Goiânia. Anais Eletrônicos... Goiânia: INTERCOM, 2016. Disponível em: <http://www.intercom.org.br>. Acesso em: 04 jun. 2017.

SILVEIRA, G.N., FERNANDES, F.B.M., NASCIMENTO, M.M. Atuar nas mídias sociais através do Facebook e do Boletim trazendo para a comunidade reflexões feminista, LGBT, étnico-raciais e de pluralismo religioso acerca das Eleições de 2014. Gira: Grupo de Estudos Feministas em Política e Educação. 2014. Disponível em: <http://repositorio.ufba.br/ri/handle/ri/23781>. Acesso em: 04 jun. 2017. 
SOARES, C. G. Raça, classe e ação afirmativa na trajetória política de militantes negros de esquerda. Política \& Sociedade, v. 11, n. 22, p. 41 - 74, 2012.

SOARES, P.F. A propagação da violência online: análise de enunciados violentos emitidos à torcedora acusada de racismo contra goleiro Aranha. Verso e Reverso, v. 30, n. 73, p. 23 - 33, 2016.

SOUZA, J.R. Personagem negra: uma reflexão crítica sobre os padrões raciais na produção dramatúrgica brasileira. Revista Brasileira de Estudos da Presença, v. 7, n. 2, p. 274 - 295, 2017.

TAJFEL, H. Social psychology of intergroup relations. Annual Review of Psychology, v.33, n. 1, p. 1 39, 1982.

TAPAJÓS, R. A comunicação de notícias ruins e a pragmática da comunicação humana: o uso do cinema em atividades de ensino/aprendizagem na educação médica. Interface-Comunicação, Saúde, Educação, v. 11, n. 2, p. $165-172,2007$.

TORRES, T.L., CAMARGO, B.V. Representações Sociais da Aids e da Terapia Anti-Retroviral para pessoas vivendo com HIV. Psicologia: Teoria e Prática, v. 10, n. 1, p. 64 - 78, 2008.

VALA, J; MONTEIRO, M.B. (Org.). Psicologia Social. Lisboa: Fundação Calouste Gulbenkian, 2013.

VALENTIM, J.P. Identidade pessoal e social: entre a semelhança e a diferença. Psychologica, v. 47, p. $109-123,2008$.

VOLOCHKO, A., VIDAL, N.P. Desigualdades Raciais na Saúde: mortalidades nas regiões de saúde paulistas, 2005. Boletim do Instituto de Saúde, v. 12, n. 2, p. 143 - 153, 2010.

\section{Como citar este artigo (Formato ABNT):}

FIGUEIRA, Talita Vieira; CASTRO, Amanda; CÓRDOVA, Ismael de; FERNANDES, Fernanda de Souza. Ataques Cibernéticos: Representações Sociais da pessoa negra na internet. Id on Line Rev.Mult. Psic., 2018, vol.12, n.41, p.551-569. ISSN: 1981-1179.

Recebido: $21 / 06 / 2018$

Aceito 28/06/2018 